\title{
Comparison of Life-Time Death Probability due to Malignant Tumors in Different Regions of China Based on Chinese Surveillance Sites
}

\author{
Ping Yuan ${ }^{1,2 *}$, Tie-Hui Chen ${ }^{1,2}$, Xiu-Quan Lin ${ }^{1,2}$
}

\begin{abstract}
Objective: To estimate and comparably analyze the life-time death probability (LDP) caused by malignant tumors in different regions in 2004 and 2014. Methods: LDP was calculated by a probability additive formula and based on an abridged life table. Data on age-specific mortality was obtained from the National Cause-of- Death Surveillance Dataset in 2014 using surveillance sites in China and data on age-specific mortality was collected from the third retrospective investigation of death cause in China in 2004. Results: LDP caused by malignant tumors, lung cancer, gastric cancer, liver cancer, esophageal cancer, colorectal, and anal cancer were $19.2 \%, 5.6 \%, 2.8 \%, 2.8 \%, 1.7 \%, 1.3 \%$, respectively. In addition, we calculated LDP caused by malignant tumors in three different regions of China. LDP caused by malignant tumors were $21.2 \%, 6.1 \%, 3.1 \%, 2.8 \%, 2.0 \%$, and $1.5 \%$ in the eastern region, were $18.3 \%, 5.5 \%, 2.7 \%, 3.0 \%, 1.5 \%$, and $1.1 \%$ in the central region, and were $16.7 \%, 4.6 \%, 2.3 \%, 2.8 \%, 1.6 \%$, and $1.2 \%$ in the western region, respectively. Additionally, LDP caused by malignant tumors in 2004 and 2015 were compared. We found that LDPs caused by malignant tumors, lung cancer, and colorectal cancer have increased in the past decade, while LDPs caused by gastric cancer, liver cancer, and esophageal cancer have experienced a decreasing trend. Conclusions: Malignant tumors were still the main cause of death in one's life time, giving rise to LDP. LDP caused by malignant tumours has two divisions. First, traditional upper digestive system cancers related to long-term chronic infection, such as esophageal cancer, gastric cancer, and liver cancer, which has shown a significant downward trend. Second, lung and colorectal cancers related to the environmental factors and lifestyle, which are on the rise.
\end{abstract}

Keywords: Malignant tumor- probability additive formula- life-time death probability- mortality

Asian Pac J Cancer Prev, 20 (7), 2021-2025

\section{Introduction}

Cancer incidence and mortality rate have increased sharply in China in recent years. In 2014, 3.804 million new cases with malignant tumors were diagnosed and 2.296 million cancer deaths were reported in China. The cancer incidence rate was 278.07 per 100,000 people. The its mortality rate was 167.9 per 100,000 people (Chen et al., 2018). The incidence and mortality of diseases are of public health and epidemiological significance for each country. But for individuals, if the cancer is unfortunately diagnosed, it will instantly become an absolute misfortune in personal life. A life-time death probability (LDP) is based on the principle of probability addition. The death probability $\left(\mathrm{P}_{0}^{\mathrm{i}}\right)$ during a life time is actually a composition index with the summation of each probability of death equal to 1 . It is not affected by population composition since it is based on the life table. LDP is quite different from the proportional mortality affected by population composition. Our previous study reported that LDP caused by a malignant tumor was $18.7 \%$ in 2004 (Yuan et al., 2014). However, as a country with a huge land area and a wide range of people's living habits in different regions, the overall data obviously cannot reflect the differences among regions. Therefore, this study was attempted to compare LDP caused by malignant tumors in different areas of China.

\section{Materials and Methods}

\section{Data Collection}

Data on age-specific mortality was obtained from the National Cause-of- Death Surveillance Dataset in 2014 using surveillance sites in China (China CDC and National HFPC, 2015). This dataset was collected through national disease surveillance system (605 monitoring stations) by the National Health and Family Planning Commission of the People's Republic of China.

Data on age-specific mortality was collected from the third retrospective investigation of death cause in the 
sample area in China in 2004 (Chen, 2008) . This survey covered 213 counties throughout the country, and it was conducted by the National Health Ministry of the People's Republic of China.

\section{Division of East, Central, and West Regions}

According to to the standards provide by the National Bureau of Statistics, China is divided into three regions, namely eastern, central, and western with respect to natural geography (Chen, 2008) .

The eastern region includes Beijing, Tianjin, Hebei, Liaoning, Shanghai, Jiangsu, Zhejiang, Fujian, Shandong, Guangdong, and Hainan.

The central region involves Heilongjiang, Jilin, Shanxi, Anhui, Jiangxi, Henan, Hubei, and Hunan.

The western region comprised of Inner Mongolia, Guangxi, Chongqing, Sichuan, Guizhou, Yunnan, Tibet, Shaanxi, Gansu, Qinghai, Ningxia, and Xinjiang.

\section{Statistical analysis}

Based on an abridge life table (Sun and Xu, 2006), the probability additive formula was taken to calculate the LDP caused by malignant tumors. The series of formulas were as follows:

$$
\begin{aligned}
& q_{x}=\sum_{i} q_{x}^{i} \\
& D_{x}=\sum_{i} D_{x}^{i} \\
& r_{x}^{i}=\frac{D_{x}^{i}}{D_{x}}=\frac{m_{x}^{i}}{m_{x}} \\
& q_{x}^{i}=r_{x}^{i} q_{x} \\
& d_{x}^{i}=r_{x}^{i} d_{x}
\end{aligned}
$$

$$
\begin{array}{r}
P_{x}^{i}=\frac{\sum_{x}^{w} d_{x}^{i}}{l_{x}} \\
P_{0}^{i}=\frac{\sum_{x=0}^{w} d_{x}^{i}}{l_{0}}
\end{array}
$$

(1), $q$ means the death probability, horn $x$ means age group, horn $i$ means the cause of death; (2) D means the actual death; (3) $m$ means mortality, $r$ means proportional mortality; (5) $d$ means death toll on the life table; (6) $l$ means survival number from the life table; and (7) $w$ means the oldest age group.

In $P_{0}^{i}$ of age group, 0 is representative of one person's LDF (Zhou TS, Chen CG ,1991).

\section{Results}

By using probability additive formula and based on abridge life table, we found that LDP caused by malignant tumors was $19.21 \%$ in China in 2014 (Table $1)$. On the abridge life table, $x$ means age group, $m_{x}$ refers to age-specific mortality, $m_{x}{ }^{i}$ indicates age-specific mortality caused by tumors, $q_{x}$ shows age-specific death probability, $l_{x}$ means age-specific survival number, $d_{x}$ is representative of age-specific death toll, $r_{x}^{i}$ represents age-specific proportional mortality caused by tumors, $d_{x}^{i}$ means age-specific death toll caused by tumors, $\sum^{d_{i}^{*}}$ refers to all-age death toll caused by tumors, $P_{x}{ }^{i}$ addresses

\begin{tabular}{|c|c|c|c|c|c|c|c|c|c|}
\hline$x(1)$ & $m_{x}(2)$ & $m_{x}^{i}(3)$ & $q_{x}(4)$ & $l_{x}(5)$ & $d_{x}(6)$ & $r_{x}^{i}(7)=(3) /(2)$ & $d_{x}^{i}(8)=(6) *(7)$ & $\sum_{x} d_{x}^{\prime}(9)$ & $p_{x}^{i}(10)=(9) /(5)$ \\
\hline $0 \sim$ & 0.0046 & 0 & 0.0046 & 100,000 & 461 & 0.0093 & 4 & 19,210 & 0.1921 \\
\hline $1 \sim$ & 0.0005 & 0 & 0.002 & 99,539 & 199 & 0.0805 & 16 & 19,205 & 0.1929 \\
\hline $5 \sim$ & 0.0002 & 0 & 0.0011 & 99,341 & 107 & 0.1394 & 15 & 19,189 & 0.1932 \\
\hline $10 \sim$ & 0.0003 & 0 & 0.0013 & 99,233 & 130 & 0.15 & 19 & 19,174 & 0.1932 \\
\hline $15 \sim$ & 0.0004 & 0 & 0.0018 & 99,104 & 178 & 0.1364 & 24 & 19,155 & 0.1933 \\
\hline $20 \sim$ & 0.0004 & 0.0001 & 0.0019 & 98,926 & 186 & 0.1337 & 25 & 19,131 & 0.1934 \\
\hline $25 \sim$ & 0.0006 & 0.0001 & 0.0031 & 98,740 & 309 & 0.1518 & 47 & 19,106 & 0.1935 \\
\hline $30 \sim$ & 0.0009 & 0.0002 & 0.0043 & 98,430 & 419 & 0.2056 & 86 & 19,059 & 0.1936 \\
\hline $35 \sim$ & 0.001 & 0.0003 & 0.0052 & 98,012 & 509 & 0.2592 & 132 & 18,973 & 0.1936 \\
\hline $40 \sim$ & 0.0017 & 0.0005 & 0.0087 & 97,503 & 847 & 0.3078 & 261 & 18,841 & 0.1932 \\
\hline $45 \sim$ & 0.0023 & 0.0008 & 0.0114 & 96,656 & 1105 & 0.3487 & 385 & 18,580 & 0.1922 \\
\hline $50 \sim$ & 0.0044 & 0.0017 & 0.0216 & 95,551 & 2,066 & 0.3813 & 788 & 18,195 & 0.1904 \\
\hline $55 \sim$ & 0.0056 & 0.0023 & 0.0275 & 93,485 & 2,570 & 0.4053 & 1042 & 17,407 & 0.1862 \\
\hline $60 \sim$ & 0.0101 & 0.0039 & 0.0495 & 90,915 & 4,498 & 0.3854 & 1734 & 16,366 & 0.18 \\
\hline $65 \sim$ & 0.0176 & 0.006 & 0.0841 & 86,417 & 7,265 & 0.3406 & 2474 & 14,632 & 0.1693 \\
\hline $70 \sim$ & 0.0282 & 0.0079 & 0.1317 & 79,152 & 10,425 & 0.2809 & 2928 & 12,157 & 0.1536 \\
\hline $75 \sim$ & 0.0437 & 0.0102 & 0.1969 & 68,727 & 13,530 & 0.2333 & 3156 & 9,229 & 0.1343 \\
\hline $80 \sim$ & 0.0805 & 0.0127 & 0.3351 & 55,197 & 18,498 & 0.1572 & 2908 & 6,073 & 0.11 \\
\hline $85+$ & 0.1664 & 0.0144 & 1 & 36,699 & 36,699 & 0.0863 & 3165 & 3,165 & 0.0863 \\
\hline
\end{tabular}
age-specific LDF caused by tumors, and $P_{0}^{i}$ is one person's LDF caused by tumors.

In addition, we discovered that LDP caused by lung cancer, gastric cancer, liver cancer, esophageal cancer, colorectal and anal cancer was 5.6\%, 2.8\%, 2.8\%, 1.7\%,

Table 1. One Person's LDP Caused by Malignant Tumor Using Surveillance Sites in China

Note: the age-specific mortality is cited by reference [3], 2015, Chapter VII,244-248. 
DOI:10.31557/APJCP.2019.20.7.2021

Difference on Life-Time Death Probability due Malignant Tumors

Table 2. Main Death Caused by Different Malignant Tumors According to Surveillance Sites in China between 2014 and 2004

\begin{tabular}{|c|c|c|c|c|c|c|c|c|}
\hline \multirow[t]{2}{*}{ Name of tumor } & \multicolumn{2}{|c|}{ Whole erea } & \multicolumn{2}{|c|}{ Eastern erea } & \multicolumn{2}{|c|}{ Middle erea } & \multicolumn{2}{|c|}{ Western erea } \\
\hline & $\begin{array}{l}\text { Mortality } \\
(1 / \text { million })\end{array}$ & $\begin{array}{c}\text { death } \\
\text { probability }(\%)\end{array}$ & $\begin{array}{c}\text { Mortality } \\
(1 / \text { million })\end{array}$ & $\begin{array}{c}\text { death } \\
\text { probability }(\%)\end{array}$ & $\begin{array}{l}\text { Mortality } \\
(1 / \text { million })\end{array}$ & $\begin{array}{c}\text { death } \\
\text { probability }(\%)\end{array}$ & $\begin{array}{c}\text { Mortality } \\
(1 / \text { million })\end{array}$ & $\begin{array}{c}\text { death } \\
\text { probability }(\%)\end{array}$ \\
\hline All malignant tumor & 155.36 & 19.21 & 175.41 & 21.18 & 144.66 & 18.29 & 139.19 & 16.74 \\
\hline Lung cancer & 43.03 & 5.56 & 49.23 & 6.13 & 41.20 & 5.47 & 35.98 & 4.62 \\
\hline Stomach Cancer & 21.10 & 2.77 & 24.14 & 3.06 & 19.91 & 2.69 & 18.05 & 2.31 \\
\hline Liver Cancer & 26.22 & 2.83 & 26.40 & 2.75 & 26.23 & 2.96 & 25.93 & 2.75 \\
\hline Esophageal cancer & 12.84 & 1.71 & 15.22 & 1.96 & 10.53 & 1.47 & 11.37 & 1.60 \\
\hline $\begin{array}{l}\text { Colorectal and anal } \\
\text { cancer }\end{array}$ & 9.65 & 1.30 & 11.42 & 1.53 & 8.27 & 1.10 & 8.83 & 1.16 \\
\hline
\end{tabular}

Note: the age-specific mortality is cited by reference [3], 2015, Chapter VII,244-248.

$1.3 \%$, respectively (Table 2). Furthermore, we calculated LDP caused by different tumors in eastern, central and western regions of China (Table 2).

In order to compare LDP in 2014 with that in 2004, we calculated LDP caused by malignant tumours, lung cancer, gastric cancer, liver cancer, esophageal cancer, colorectal and anal cancer in China in 2004 was $18.7 \%, 4.5 \%, 3.6 \%$, $3.3 \%, 2.3 \%, 1.1 \%$, respectively (shown in table 3 ). Furthermore, we also calculated LDP caused by different tumors in eastern, central and western regions (shown in Table 3).

\section{Discussion}

To the best of our knowledge, this was the first epidemiological study comparing LDP caused by malignant tumors in different regions of China. The top 5 cancer sites were similar in eastern, central and western regions, which were lung, liver, stomach, esophagus and colorectum. LDP caused by malignant tumors decreased in all three regions, but some differences were observed with respect to a specific cancer. LDPs caused by esophageal cancer and colorectal cancer were higher in western region than central and east regions. LDP caused by liver cancer was slightly higher in central region than in east and west regions. This finding may be due to the differences in lifestyles, geographical locations and living environment, economic level, medical resource allocation, diagnosis, and treatment level (Jemal et al., 2010; Zeng et al., 2015). The eastern region is well-developed region with a high standard of living and a preference Western lifestyle. In recent years, the obesity rate in the eastern region is on the rise (Zheng et al., 2018; Yang et al., 2017). The potential factors linking obesity to cancer might cause insulin resistance, a chronic, subclinical inflammation in the visceral fat, and alterations on the tumor microenvironment driving tumor progression via the stimulation of cell survival/anti-apoptosis, cell proliferation, angiogenesis, and invasion/metastasis of cancer cells (Ungefroren et al., 2015). Higher LDP caused by liver cancer in central region may be related to its humid local climate and the consumption of mildew food by people living there.

Higher LDP in 2014 (19.21\%) than that in 2004 $(18.73 \%)$ attracted public attention. LDPs caused by lung cancer and colorectal cancer have increased in the past decade, while LDPs caused by gastric cancer, liver cancer, and esophageal cancer have experienced a decreasing trend. Strengthening physical activity, maintaining healthy weight, promoting healthy eating patterns, reducing meat food, increasing the intake of fruits and vegetables, stopping smoking, limiting alcohol consumption, and carrying out cancer screening are considered as effective measures for preventing and controlling malignant tumors.

In our daily life, we need an indicator to measure the risk of death caused by cancers. LDP is just a good indicator, which refers to the probability of death for a particular person from a certain death cause in the presence of various death causes. It is based on the principle of probability addition, but not affected by population composition and considering the risk of death competition. Cumulative mortality or cumulative risk

Table 3. 2004 Main Death Caused by Different Malignant Tumors on Surveillance Sites in China

\begin{tabular}{|c|c|c|c|c|c|c|c|c|}
\hline \multirow[t]{2}{*}{ Name of tumor } & \multicolumn{2}{|c|}{ Whole erea } & \multicolumn{2}{|c|}{ Eastern erea } & \multicolumn{2}{|c|}{ Middle erea } & \multicolumn{2}{|c|}{ Western erea } \\
\hline & $\begin{array}{l}\text { Mortality } \\
(1 / \text { million })\end{array}$ & $\begin{array}{c}\text { death } \\
\text { probability }(\%)\end{array}$ & $\begin{array}{l}\text { Mortality } \\
(1 / \text { million })\end{array}$ & $\begin{array}{c}\text { death } \\
\text { probability(\%) }\end{array}$ & $\begin{array}{l}\text { Mortality } \\
(1 / \text { million })\end{array}$ & $\begin{array}{c}\text { death } \\
\text { probability(\%) }\end{array}$ & $\begin{array}{l}\text { Mortality } \\
(1 / \text { million })\end{array}$ & $\begin{array}{c}\text { death } \\
\text { probability(\%) }\end{array}$ \\
\hline $\begin{array}{l}\text { All malignant } \\
\text { tumor }\end{array}$ & 135.88 & 18.73 & 154.69 & 20.24 & 135.85 & 19.26 & 111.39 & 15.81 \\
\hline Lung cancer & 30.83 & 4.47 & 37.85 & 5.17 & 30.79 & 4.53 & 21.76 & 3.34 \\
\hline Stomach Cancer & 24.71 & 3.62 & 26.71 & 3.67 & 25.17 & 3.85 & 21.53 & 3.26 \\
\hline Liver Cancer & 26.26 & 3.25 & 28.37 & 3.32 & 26.82 & 3.45 & 22.83 & 2.91 \\
\hline Esophageal cancer & 15.21 & 2.25 & 16.67 & 2.29 & 15.52 & 2.42 & 12.92 & 1.98 \\
\hline $\begin{array}{l}\text { Colorectal and } \\
\text { anal cancer }\end{array}$ & 7.25 & 1.11 & 8.67 & 1.24 & 7.19 & 1.08 & 6.07 & 0.95 \\
\hline
\end{tabular}

Note: the age-specific mortality is cited by reference [4], 2008, Chapter VII, P52-53. 
(Andersen et al., 2012; Kim, 2007; Latouche et al., 2013) is another indicator that can indicate the seriousness of a certain death cause, but it does not take into account the competition risks. On the other hand, in the analysis of time event data, there is a competitive risk. Some subjects may experience competition risks when the events of interest are excluded by different types of events that had occurred previously (Kohl, 2015). As it can be seen from Table 2, the mortality (26.40/10 million) in the eastern area was higher than that (24.14/10 million) of stomach cancer, but LDP caused by liver cancer $(2.75 \%)$ was lower than that caused by gastric cancer $(3.06 \%)$. The main reason for this finding might be as follows: the mortality of liver cancer in eastern area (13.96/10 million) was twice than stomach cancer (4.40/10 million) among sufferers aged less that 40 to 45 years old; however, the mortality of stomach cancer (124.55/10 million) was higher than that of liver cancer (100.65/10 million) among patients aged older than 70 to 75 years old, indicating that people died from liver cancer were younger, but people died from gastric cancer were older. Therefore, considering the competitive risk death, it can be seen that LDP caused by liver cancer was lower than that caused by gastric cancer.

The current investigation; however, was confronted with a number of limitations. The monitoring points for mortality by age in 2004 and 2014 were different (213 in 2004 and 605 in 2014), which may lead to differences in age specific mortality. Nevertheless, the National Disease Surveillance System was led by the National Health and Family Planning Commission in 2013 to integrate the death statistics system of the Ministry of Health and the National Disease Surveillance System. Death rate by age in 2014 was a continuation of the work of the Ministry of Health's death statistics system in 2004, with the same criteria for all disease classifications, working methods, and regional divisions, increasing the comparability of 2004 and 2014.

In conclusion malignant tumor is still the main cause of death among humans, giving rise to LDP. LDP caused by malignant tumours has two divisions. First, traditional upper digestive system cancers related to long-term chronic infection, such as esophageal cancer, gastric cancer, and liver cancer, which has shown a significant downward trend. Second, lung and colorectal cancers related to the environmental factors and lifestyle, which are on the rise. Therefore, cancer prevention and treatment strategies should be implemented to improve people's health in China. These strategies can be provision of health education, promotion of healthy lifestyles such as having healthy diet and moderate exercise, changing bad living habits, controlling environmental risk factors, and establishing environmental health monitoring systems.

\section{Acknowledgements}

This research was supported by Tianshu Zhou (Fujian center for disease control and prevention).

There was no financial support for this study.

\section{Authors' contributions}

Conception and design: YUAN Ping

Acquisition of data (acquired and managed patients, provided facilities, etc.): CHEN Tie-hui

Analysis and interpretation of data (e.g.statistical analysis, computational analysis): YUAN Ping, LIN Xiu-quan.

Writing, review, and/or revision of the manuscript: YUAN Ping

\section{Disclosure of potential conflicts of interest}

The authors disclose no potential conflicts of interest.

\section{References}

Andersen PK, Geskus RB, de Witte T, Putter H (2012). Competing risks in epidemiology: possibilities and pitfalls. Int J Epidemiol, 41, 861-70.

Chen WQ, Sun KX, Zheng RS, et al (2018). Report of cancer incidence and mortality in different areas of China, 2014. Bull Chin Cancer, 27, 1-14.

Chen Z (2008). The third review sampling investigation report of death. Chapter I. Beijing union medical university press, pp 8-9.

Chen Z (2008). The third review sampling investigation report of death, Chapter VII. Beijing union medical university press, pp 52-3.

China Center for Disease Control and prevention, Chronic Non-communicable Disease Prevention and Control Center, National Health and Family Planning Commission statistical information center (2015). Chinese death surveillance data set (2014), Chapter VII. Beijing popular science press, pp 244-8.

Jemal A, Center MM, DeSantis C, Ward EM (2010). Global patterns of cancer incidence and mortality rates and trends. Cancer Epidemiol Biomarkers Prev, 19, 1893-907.

Kim HT (2007). Cumulative incidence in competing risks data and competing risks regression analysis. Clin Cancer Res, $15,559-65$.

Kohl M, Plischke M, Leffondré K, Heinze G (2015). PSHREG: A SAS macro for proportional and nonproportional subdistribution hazards regression. Comput Methods Programs Biomed, 118, 218-33.

Latouche A, Allignol A, Beyersmann J, Labopin M, Fine JP (2013). A competing risks analysis should report results on all cause-specific hazards and cumulative incidence functions. J Clin Epidemiol, 66, 648-53.

Sun ZQ, Xu YY (2006). Health Medical Statistics. People 's Health Publishing House, pp 377-81.

Ungefroren H, Gieseler F, Fliedner S, Lehnert H (2015). Obesity and cancer. Horm Mol Biol Clin Investig, 21, 5-15.

Yuan P, Chen TH, Chen ZW, Lin XQ (2014). Calculation of life-time death probability due malignant tumors based on a sampling survey area in China. Asian Pac J Cancer Prev, 15, 4307-9.

Yang HM, Lin R, Wu D, et al (2017). Changes in overweight and obesity among children aged 3 6 years in Shenyang in 2004 and 2014. China Health Stat, 34, 931-2, 935.

Zhou TS, Chen CG. An indicator of death-cause composition- a life-time death probability (1991). China Health Statist, 8, 45-6.

Zeng H, Zheng R, Guo Y, et al (2015). Cancer survival in China, 2003-2005: a population-based study. Int J Cancer, 136, 1921-30.

Zheng KJ, Shi LL, Wu XL, et al (2018). The analysis on the prevalence trend of overweight and obesity in primary and 
middle school students in Baoshan District, Shanghai, 2009-

2014. Matern Child Health Care China, 33, 413-6.

\section{(ब) $(1)$}

This work is licensed under a Creative Commons AttributionNon Commercial 4.0 International License. 